\title{
Psychosocial problems among survivors and suggested interventions for coping with child sacrifice in Uganda
}

\author{
Ronald Luwangula, Paul Bukuluki*, Justus Twesigye \\ Department of Social Work and Social Administration, Makerere University, Kampala, Uganda \\ *E-mail address: pbukuluki@ss.mak.ac.ug
}

\begin{abstract}
Child sacrifice remains a profound challenge to human socio-cultural rights. The increasing problem manifests in several dimensions. It results to death of some children, disappearance of others, children with life-time deformations and/or irreversible disabilities, to the detriment of the child and his/her immediate and extended families. Each child and family victim faces unique and diverse traumatic experiences and peculiar challenges, so are the coping mechanisms, where coping ever occurs. This paper identifies some of the challenges contingent upon cases illustrated. Analysis of the challenges faced and possible coping is guided by a framework of theories that underpin coping with traumatic experiences. These include; the play therapy for children, cognitive-behavioural therapy, the stage specific model, narrative coping mechanisms, and support and self-help groups therapy. Hence, a reflection on how the victims, survivors and their families/caregivers actually cope in practice, based on documented cases is made.
\end{abstract}

Keywords: Child protection; psychosocial; coping; child sacrifice

\section{INTRODUCTION}

This article is structured into five inter-linked sections, namely; background, conceptualization of child sacrifice as traumatic event, challenges faced by survivors of child sacrifice and their families, suggested interventions for survivors of child sacrifice and their families and the conclusion.

\section{BACKGROUND}

The practice of child sacrifice is common in Uganda (HumaneAfrica, 2013). Child sacrifice is defined as the "killing, mutilation, removal of organs or body parts of a child for sale or for the purposes of witchcraft, rituals or any harmful practices" (Ibid, 2013). Shedding of blood of some kind has for long been a common practice among many communities of Uganda and is often associated with the belief in celebrating success e.g. on buying new car, exorcising evil spirits, or protecting individuals and families against misfortunes (Binoga, 2009). Although such practices in many communities often involve killing of domestic animals 
such as chickens and goats, they are increasingly involving human beings as the sacrifice (Binoga, 2009; HumaneAfrica, 2013).

The practice of child sacrifice is generally unacceptable, legally, culturally, morally and religiously in Uganda. Moreover, it leads to much terror, suffering, and distress that often overwhelm coping capacities of the survivors and their families. The unique circumstances such that surround the practice of child sacrifice may account for differences among survivors and their families in coping with the consequences associated with the practice.

\section{PREVALENCE OF CHILD SACRIFICE IN UGANDA}

According to Binoga (2009), child sacrifice is highly prevalent in Uganda. A large number of children is frequently trafficked, kidnapped, abducted and murdered. Binoga (2009) also reported that Police records in Uganda indicate that 03 cases involving homicide recorded in 2007 were suspected to be related to human sacrifice. At least 25 similar cases were also recorded in 2008 and that in both instances, most of the dead people were children. Furthermore, since 2009, approximately 23 adults and children have been killed under circumstances that suggest human sacrifice (Ibid, 2009). A total of 13 children died in circumstances associated with human sacrifice in the period between January and November 2009 alone. In the same period, a total of 753 children went missing from their homes and were suspected to have been sacrificed. Although 635 of them were later traced and confirmed alive, the rest remain unaccounted for and could therefore have been sacrificed. HumaneAfrica (2013) has similarly reported that "there were 9 cases of child mutilation or sacrifice and 4 cases of mutilation or sacrifice involving adults in Uganda in the period January to November 2012." It is also noted that participants in the HumaneAfrica (2013) study indicated having observed at least 20 cases of mutilated people, seeing a mutilated body, being exposed to an attack at the scene of sacrifice, using the child's body part for harmful practices or confessing that they killed a child. The participants also reported having observed at least 77 cases in which the children's bodies had been dismembered, had missing blood tissues or body parts or had been removed from a corpse. These findings indicate the highly traumatizing experience of child sacrifice as discussed below.

\section{CHILD SACRIFICE AS A TRAUMATIC EXPERIENCE}

Child sacrifice is conceptualized as a traumatic experience for its survivors, their families and other members of the public. The interventions suggested later, are also in keeping with this conceptualization of child sacrifice. According to Tuval-Mashiach et al. (2004: 280), a traumatic event "confronts people with extremely unusual stress, and requires coping with a new, unexpected, and unfamiliar situation" (also see, American Psychiatric Association, 2013).Tucker-Ladd (1996) refers to the term trauma as "a very disturbing, stressful experience that may come from a real external threat (upsetting physical or psychological circumstances) or one's interpretation or even false perceptions of circumstances, dangers and faults (a subjective experience)". A traumatic experience may be intense for a long time or only moderately upsetting for a few days or weeks.

The American Psychiatric Association (2013) shows that Post-Traumatic Stress Disorder (PTDS) involves people who have been in serious jeopardy and experienced intense fear, people who have personally been exposed to possible death and escaped or been intimately involved 
with a loved one in which such dire situation situations occurred. It is plausible that survivors of child sacrifice often experience situations such as those stated above. Other events that are similarly associated with trauma include excessive torture, sexual abuse, emotional abuse and social rejection among children (Tucker-Ladd, 1996).

In particular, rejection of survivors of child sacrifice often aggravates their traumatic experiences. Affected families may, for example, feel fed up and lose hope in the child survivor because of the excessive costs of the treatment, care and rehabilitation of the latter. According to an informal conversation with staff of ANPPCAN (African Network on Prevention and Protection of Children against Abuse and Neglect) Uganda, many families are generally materially and financially too poor to provide protection for their members and survivors of sacrifice. In addition, child sacrifice is often associated with chronic physical and mental disability among the survivors and their families. Children may have to live without some of their body parts, which precipitate feelings of anxiety, emptiness, fear and stigma. Such emotional states are at times worsened by a weak justice system that is unable to effectively try cases involving child sacrifice.

\section{PSYCHOSOCIAL PROBLEMS ASSOCIATED WITH CHILD SACRIFICE}

Based on the cases highlighted in this paper, a number of psychosocial problems associated with child sacrifice among survivors and their families are discussed below:

\section{(a) Dissatisfaction with a weak justice system:}

The affected individuals and their families usually are unconvinced with trials of cases involving allegations of child sacrifice. The dissatisfaction is sometimes associated with delays in investigating and prosecuting such cases and giving sentences to offenders that survivors and their families consider to be disproportionate to the trauma suffered. For example in the case of Samson and Lean ${ }^{1}$ (pseudonyms).

\section{In this case, Samson and Lean lost their only son to sacrifice right at their very doorstep. The killer of their son was arrested and eventually released. This couple faced unimaginable hardships after the loss of their son aggravated by lack of justice coupled with negative and accusatory reactions by some people whenever the couple would speak out against human sacrifice}

The eventual release of the suspected offender was very unsatisfactory to the affected family. Because survivors and their families perceive the judiciary as the supreme source of justice, dissatisfaction with their services may engender many negative consequences. Such consequences include feeling of mistrust, hopelessness, injustice, incompetence among the affected individuals and families. Unlawful conduct such as mob justice targeted at suspects involved in child sacrifice may also be a result of dissatisfaction with a weak justice system in Uganda. In contrast with the above case, John (not real names) in another case from Bugiri district had his penis cutoff in 2009. Although his family expressed pleasure that his case was tried, they expressed concern that the 15-years sentence was rather lenient to the offender. In John's case as reported by ANPPCA Uganda ${ }^{2}$

\footnotetext{
${ }^{1}$ http://advocacynet.org/wordpress-mu/jjenifer/2011/07/31/meet-the-volunteers-of-the-gideon-foundation-against-childsacrifice/ [Accessed 28.02.2012]

${ }^{2} \mathrm{http}$ ://www.anppcanug.org/child-protection-services/
} 
John survived after being sacrificed by a traditional witchdoctor who lived in their neighborhood in Bugiri district. In 2009, John's father and other family members had gone for burial and left John and other older siblings at home. John was quite familiar with the traditional witchdoctor (their neighbor) and used to play with his children. So when the traditional witchdoctor called John, he did not hesitate to come along with him. When John's parents returned from burial, they realized that he was missing from home, and decided to conduct a village search, since his siblings remembered that he was called last and went with the witch, who was nowhere to be seen at that particular time. The whole family began looking for him in the evening. Just a few meters from the Banana plantation, his uncle found him lying unconscious in the bush in a pool of blood and his penis cut off. For over one year, John received treatment from International Hospital Kampala through Hope Ward (a charity Ward that offers free medical treatment to extremely vulnerable persons). While at IHK, he underwent several surgeries in an attempt to reconstruct the urinary tract system (Penis). Alongside IHK (Hope ward) medical treatment, ANPPCAN Uganda, provided John with psychosocial support to enable him recover. John was later referred to CORSU Rehabilitation Centre at Kisubi hospital with recommendation for further surgery. At CORSU, Johns' penis was reconstructed and continued undergoing medical checkups to ensure proper healing. According to the surgeons, an appropriate size of a penis (adult size) has been constructed to suit his later old age. (The penis constructed will not grow but remain constant).

The lack of evidence to support trial of cases involving child sacrifice contributes to the dissatisfaction with the justice system among survivors and families. For example, Elinor (pseudonym) in 2009 was a 15 year old girl in Soroti district who was raped, murdered and beheaded in $2009^{3}$. Whereas Police subsequently traced Among's murderers with help of the cell phone that was found on Elinor's body, the cases was not satisfactorily tried in the courts of law. Moreover, all the suspected murderers were eventually released and reportedly, they all continue to live in Soroti district. Agnes (Elinor's caretaker and upbringing guardian) described Elinor's murder as "haunting" and remained perplexed as to: "how someone could do something of that kind and go scot free under the guise of lack of evidence".

\section{Elinor's case $e^{4}$}

Elinor, a 15 year old girl who had been raised by caretaker and upbringing guardian (Agnes-pseudonym) was raped, murdered and beheaded in 2009. Elinor was then staying at a Catholic girl's hostel/boarding school in Soroti district when one night in February 2009 someone she trusted (said to be a boyfriend with his friends) came to the hostel to get her and she left with them. She never returned. Her headless body was then found in a grassy area in Soroti district. Her body was found quickly because one of the persons who murdered Elinor had dropped his cell phone on her body. So after the murder, the person who wanted Elinor's head was calling this person to arrange the exchange. Students heard this cell phone ringing in the bushes and then alerted others. Agnes heard that a body was found without a head but initially she didn't think much of it since Elinor was presumably safe at the boarding school. But then she was called to go and identify Elinor's body. It was said that the murderers had arranged to trade Elinor's head in Sudan but when they failed to transport it, the threw it over a fence where it was found separate from the body in the bush.

\footnotetext{
${ }^{3} \mathrm{http}: / /$ advocacynet.org/wordpress-mu/jjenifer/2011/07/31/meet-the-volunteers-of-the-gideon-foundationagainst-child-sacrifice/ [Accessed 28.02.2012]

${ }^{4} \mathrm{http} / / /$ advocacynet.org/wordpress-mu/jjenifer/2011/07/31/meet-the-volunteers-of-the-gideon-foundationagainst-child-sacrifice/ [Accessed 28.02.2012]
} 


\section{(b) Family stigma}

Members of the public often stigmatize families affected by child sacrifice. For example, in the case of Samson and Lean, when their son was murdered and sacrificed, members of the community/society shunned them. Yet, the distress associated with the loss of their son suggests that they needed social support to enable them cope with the loss (Tucker-Ladd, 1996; Shalev, 2002). The family in some instances, instead, suffered negative and accusatory reactions from members of the public. Family stigma also aggravated the emotional problems such as hopelessness and helplessness they experienced.

\section{(c) Internalized Feelings of Insecurity}

Child sacrifice results in internalized feelings of insecurity among the survivors and their families. For example, ANPPCAN reported that John (not real names) and his family live in perpetual fear ever since they suffered an incident of child sacrifice in 2009. Although the family was reported to be somehow satisfied with the way the case was tried and the suspected offender prosecuted (sentenced to15 years in jail), they believe that he might eventually for example, hurt them further, when he is released. The family also believes that a 15 -years sentence was too short to compensate for the offence committed to the family. As a consequence of the above, John's family has had to shift to another district for their physical and emotional protection as they thought they could be hurt by the culprit's family. Moreover, the sentence had further strained the relationship between the two families. The relocation to a new district and disintegration of the family as John is presently living separately with the rest of his family imply they experience various disadvantages, such as, loss of social capital, enculturation stress, loss of identity, and possible discrimination in the new home settings. Closely related to the above case, Shaban (pseudonym) (case details reflected below), has been kidnapped many times and him and the family live in perpetual fear. His family and ANPPCAN reached a point of requesting the Police to offer increased security for their child.

\section{Shaban's Case reported by Uganda Radio Network website (2009); Uganda Police (2010)}

Parents of Shaban, a 9 year old boy who escaped being sacrificed in Mukono district asked the police to protect him against people they believe want to harm him. Shaban was kidnapped from his parents' home in Kyebando on December 28, 2008 by one Muwanga on motor cycle and taken to a shrine in Kirinya in Bweyogerere, but escaped sacrifice because he is circumcised. Shaban's mother said unknown people were trying to kidnap the boy. In the second attempt, Shaban was kidnapped from the home of the African Network for the Prevention and Protection against Child Abuse and Neglect (ANPPCAN) where he had been taken for safe custody. The boy's mother was called after the boy went missing from ANPPCAN but by the time she arrived the boy had escaped from his captors and returned to the center. In the latest incident, Shaban's captors used a chemical in a handkerchief that made him pass out. Shaban's captors took him to a forest from where he escaped and found himself in Natete, but traced his way back home. An officer with ANPPCAN emphasized the need to step up security for the protection of Shaban and other children since the people stalking Shaban seemed determined to harm him. At the time of this reporting, Shaban was being kept in-doors.

\section{(d) Family Conflict}

In some instances where family members are accomplices to child sacrifice, there is aggravated family conflict. Family conflict is associated with feelings of insecurity, loss of social support, betrayal and anger. In some cases, there is marital distabilisation and 
disintegration if one of the parents is suspected to be involved in the practice of child sacrifice. As a result, the affected children experience emotional distress especially if they believe that they are the cause of the family conflict. When the suspected individual is the breadwinner, the livelihood of the entire family may be greatly compromised.

\section{e) Chronic Disability}

Child sacrifice is associated with chronic physical and mental disability among survivors. For example, John (case described above) lost his penis. Despite indispensable efforts by the medical team to treat him, he is unlikely to live a normal sexual life. Surgeons have particularly constructed an artificial penis for John to suit his later old age implying that it may be disproportional to his current age and body size (ANPPCAN Uganda ${ }^{5}$ ). The emotional loss associated with losing body parts such as a penis may also be aggravated by the use of appliances and may also be chronic. John's family expressed concern about the possibility that their son will not be able to produce children and that such a state of affairs will aggravate family stigma associated with child sacrifice.

\section{f) Unresolved Grief}

Child sacrifice leads to unresolved psychological consequences such as grief and bereavement among survivors and their families. In an interview with ANPPCAN, it was noted that John, for example was experiencing unresolved grief over the loss of his penis. In addition, he re-experienced the trauma whenever he got in contact with the suspected offenders. In one instance, when John attended a court session, seeing the suspected offender caused to run away from the court premises. Yet, there is a paucity of agencies that carry out rehabilitation of survivors of child sacrifice in Uganda (ANPPCAN Uganda ${ }^{6}$ ).

In addition to the above, the victim and survivor of child sacrifice suffers a set of psychological challenges and reactions. For example, some find difficulties to socialize, develop lack of trust for not only strangers but any adults, and worst of all, failure to cope with or pursue education careers. John's case attests to this. For he trusted the witch doctor before the incident but following the incident, the boy is reported to be having difficulties in trusting strangers, something that is impacting negatively on his socialization with his fellow children but also with community members.

\section{g) Excessive Costs of Treatment}

Child sacrifice is associated with excessive costs of treatment for survivors and their families. For example, the physical and psychological impairments among survivors necessitate payment of exorbitant medical bills, which many poor families cannot afford. In the case of John, the most financial support was provided by International Hospital Kampala and CORSU. In contrast, in the case of Alex (pseudonym), medical bills were paid by his father who had to painfully sell the family house to pay for Allan's medical expenses and left his job in order to care for his son. (Ljubica, Vujadinovic et al. 2011). In instances where families are unable to meet costs of treatment and there are no alternative sources of financial support, children may not be able to survive the physical impairments attributed to child sacrifice.

\footnotetext{
${ }^{5} \mathrm{http}: / /$ www.anppcanug.org/child-protection-services/

${ }^{6} \mathrm{http}: / / \mathrm{www}$.anppcanug.org/child-protection-services/
} 


\section{INTERVENTIONS FOR SURVIVORS OF CHILD SACRIFICE AND THEIR FAMILIES}

We suggest that the following psychosocial related interventions may be helpful in assisting the survivors of child sacrifice and their families to cope:

\section{(i) Play therapy}

Play therapy is one of the widely used treatments for children who have experienced trauma. According to Virginia Axline ${ }^{7}$, play therapy is based on the assumption that "play is the child's natural medium of self-expression, thus, children are given opportunity to 'play out' their feelings and problems". Children subsequently 'talk out' their difficulties. Garofolo ${ }^{8}$ notes that children who have experienced traumatic events need to express and understand their feelings since this naturally and safely enables their healing processes to begin. Play therapy also normalizes the act of receiving help. It also enables children to internalize caring and to learn healthy self-care skills.

Child play therapy is useful to children faced with varying circumstances such as those who (i) have been abused sexually, physically or emotionally, (ii) are dealing with issues of loss, such as illness or death of a loved one, (iii) have been hospitalized, and (iv) have been diagnosed with mental disorders such as Attention Deficit Disorder (Play Therapy for Children website). Child play therapy is apt for emotional problems such as excessive anger, worry, sadness or fear, behavioral problems such as separation anxiety, excessive shyness, and psychological problems such as low self esteem. These problems are common among survivors of child sacrifice.

\section{(ii) Cognitive-Behavioral Therapy}

Cognitive-behavioral therapy is another suggested treatment for the survivors of child sacrifice and their families. It aims at managing inappropriate or irrational thinking patterns and maladaptive behavior associated with traumatic experiences. These often include manifest consequences such as anxiety, depression and anger among survivors of child sacrifice (The Gale Encyclopedia of Mental Disorders, 2003; Dass-Brailsford, 2007:54).

Cognitive therapy was developed by Aaron Beck in the 1960s and is a psychosocial (both psychological and social) therapy that assumes that faulty thought patterns (called cognitive patterns) cause maladaptive behavior and emotional responses that warrant treatment that focuses on changing thoughts in order to solve psychological and personality problems (The Gale Encyclopedia of Mental Disorders, 2003). Behavioral therapy on the other hand is "a similarly goal-oriented, therapeutic approach that treats emotional and behavioral disorders as maladaptive learned responses that can be replaced by healthier ones with appropriate training".

Cognitive-behavioral therapy (CBT) therefore encompasses an appropriate mix of the behavior modification and cognitive restructuring approaches. Cognitive-behavioral therapy is a recommended for treatment for a number of mental disorders such as depression and PTSD. By using techniques such as systematic positive reinforcement, modeling, validity testing, guided discovery and cognitive rehearsal among others, the cognitive-behavioral therapist supports patients examine and change their maladaptive thoughts and behaviors.

\footnotetext{
${ }^{7} \mathrm{http}: / / \mathrm{www}$. playtherapyforchildren.com/ [Accessed 05.03.2012]

${ }^{8} \mathrm{http}: / /$ www.playtherapyforchildren.com/ [Accessed 05.03.2012]
} 


\section{(iii) A Stage-Specific Model}

A stage-specific model (Dass-Brailsford, 2007) is another intervention that may be effective in managing trauma among the survivors of child sacrifice. The model acknowledges that traumatic events such as child sacrifice results in relational difficulties, a general lack of trust, and feelings of insecurity.

The model describes trauma recovery as progressing through three broad stages. The first is establishing a client's safety and stabilization. The second stage is remembering, exploring, and mourning past traumas (reconstructing the traumatic story) and the third stage is reconnecting between the survivor and his/her family and community (also perceived as expanding and revitalizing the relational world of the client (Herman 1997, cited in DassBrailsford, 2007; Herman, 1992). This treatment model/approach referred to by Webber et al (2006) as Triphasic Model (citing Baranowsky, \& Gentry, 2002; Baranowsky, Gentry, \& Schultz, 2004; Herman, 1992) is appreciated as one of the most effective for survivors of trauma.

The first stage of safety involves empowering and connecting survivors with support systems. The goal of helping in this stage is to support the survivor to make a gradual shift from unpredictable danger to reliable safety (Webber et al, 2006). Documented cases show that some survivors develop a strong sense of insecurity in the location they were at the time the sacrifice took place, which may require the above intervention techniques. They feel the child survivor is insecure and so is the entire family, for instance in John's case.

Considering that trauma-related problems undermine attachments and often create a vicious circle of spiraling distress leading the traumatized person to feel increasingly alienated from sources of support, Allen (a Senior Staff Psychologist with The Menninger Clinic) argues for secure and stable relationships as good foundation for healing (Allen, 2010). Remembrance and Mourning focuses on past issues, in particular the traumatic event that causes a client's difficulties (Dass-Brailsford, 2007).

In this phase, the victim/survivor is encouraged to recall traumatic memories and reconstruct the story of his or her trauma in somewhat relative detail with the clinician bearing witness to the client's experiences to help him or her find the strength to heal (Webber et al, 2006; Dass-Brailsford, 2007, citing Herman, 1997). A clear understanding of the client's story is presumed to be helpful in enabling the therapist to better understand the client's situation, which are both essential for effective helping. Encouraging the survivor to recall and tell his/her memories in some detail is premised on the belief that clients who avoid their traumatic memories may stagnate and not improve in therapy (Ibid). A number of techniques are suggested to facilitate the client make a full recall of the traumatic memory. These include flooding (particularly for individuals who have experienced a single incident of trauma), testimony (particularly for who have experienced political trauma), and hypnotherapy (particularly for client's whose gaps in memory unable them from fully recalling traumatic events) (Ibid).

Herman (1997) states that mourning is an inevitable and a necessary aspect of healing; the client is thus encouraged to accept grief as an act of courage rather than defeat although sometimes clients may resist mourning in order to "deny handing victory over to the perpetrator" (Herman, 1997: 188 cited in Dass-Brailsford, 2007: 60). Similarly, mourning has a "restorative power by helping clients come to terms with fantasies of revenge" (Ibid).

Reconnection focuses on "helping the survivor to reconcile with the past and to overcome negative aspects of the self that may have been imposed by the trauma with a goal to remain autonomous while simultaneously developing connections" (Dass-Brailsford, 2007 citing Herman, 1997). The stage focuses on enabling the victim/survivor redefine oneself in the 
context of meaningful relationships (Webber et al, 2006). Reconstructing the ability to trust both self and others central for the survivor to expand and revitalize his or her relational world (Dass-Brailsford, 2007).

Some clients, in the reconnection stage of recovery, "choose to become social activists and commit to a survivor mission pursuing the eradication of violence. In joining such groups, the survivor satisfies a yearning for connection while creating opportunities to ally with others who share a common purpose" (Dass-Brailsford, 2007). In particular, joining survivor groups may be appreciated as a "constructive way of transforming the meaning of personal tragedy" (Ibid: 61 citing Herman, 1997). In the case of Samson and Lean presented in earlier, following the loss of their only son to child sacrifice, in 2006 they started a Foundation against Child Sacrifice ${ }^{9}$. The Foundation has since created awareness about dangers associated with human sacrifice and advocated against the practice.

\section{(iv) Narrative therapy}

Tuval-Mashiach et al (2004) indicate that narrative therapy is essential for coping with distress in the early phase following traumatic event. They also state that when clients tell their life-stories, their identities are expressed and get known to others (cited Lieblich et al, 1998). Most significant, the client's narrative is informative about his/her degree of proneness to psychological and emotional difficulties (Howard 1991:191, cited in Tuval-Mashiach et al, 2004). Appreciating that narrative therapy focuses on the client's life-story as the main tool for a therapeutic change, depending on whether the survivor is capable of holding a coherent, meaningful, and dynamic narrative or rather narrates a flawed story offers a better understanding and basis for client support (Ibid, 2004).

Levin (2004) observed that 'connection' and opportunities to talk facilitate coping with trauma. He proposes a number of coping strategies such as mobilizing support, reaching out and connecting with others, especially those who may have shared the stressful event, talking about the traumatic experience with empathic listeners, expressing emotions such as crying, humor, engaging in prayer and/or meditation, listening to relaxing guided imagery, and maintaining balanced diet and sleep cycle. Levin also indicates that individual, group, or family counseling are essentially therapeutic for many survivors of traumatic events such as child sacrifice.

Additionally, Shalev (2002) suggests that helpers to encourage survivors of trauma to verbalize and share their stories with other people and to acknowledge that while telling the story is stressful it may also create an emotional bond that reduces the survivor's isolation. Survivors are also encouraged to associate and relate with other people.

\section{FOCUS ON STRESS MANAGEMENT}

While some literature has focused on professional trauma treatment techniques, others have paid attention to ways of handling stress (Tucker-Ladd, 1996). Stress management includes techniques such as relaxation techniques or use of tranquilizing drugs to slow and calm down the survivor especially if the stress is short-lived. It also includes dealing with underlying causes and history of the stress (Ibid). Tucker-Ladd (1996) also reports that having/increasing

\footnotetext{
${ }^{9} \mathrm{http} / / /$ advocacynet.org/wordpress-mu/jjenifer/2011/07/31/meet-the-volunteers-of-the-gideon-foundationagainst-child-sacrifice/ [Accessed 28.02.2012]
} 
positive/interesting experiences and feelings (such as higher self-esteem, fun, play, deeper social contact, etc.) and decreasing the negative emotions, including stress, anxiety, depression, anger and dependency is an effective way of managing stress. Tucker-Ladd (1996) also cautions that serious psychological problems necessitate seeking professional help immediately and that self-help does not substitute professional help in very severe cases.

\section{SUPPORT AND SELF-HELP GROUPS}

Tucker-Ladd (1996) noted that support and self-help groups may be effective in managing trauma. Thus, survivors are encouraged to share their feelings with supportive non-evaluative friends, family members, peers, teachers, or a professional counselor. The underlying assumption is that sharing a traumatic experience is therapeutic to the client. Rachman (1978) cited in Tucker-Ladd (1996) stated that "we are less afraid and have more courage when someone is with us holding our hand". Furthermore, Tucker-Ladd (1996) cites a 10-year study at Stanford University which revealed that cancer patients who participated in a support group lived twice as long as those who did not participate in such groups. Using social support groups appears to be a common approach to coping with problems of living including sacrifice, in the Ugandan context. The extended family, friends, workmates and, the clergy, often provide emotional and material support to individuals and families faced with traumatic experiences such as child sacrifice.

However, considering that access to such services by victims and survivors of child sacrifice in Uganda is questionable on many fronts (e.g. inadequacy of skilled professionals, unaffordable cost, poor geographical and financial access, ignorance about the needed services and their location, and so on), not likely that many ideally qualifying parties really consume the services. For this reason, coping strategies adopted seem to have taken a different turn determined by circumstances faced by the different families. To a great extent, it can be contended that coping has in many instances been limited to what Shalev (2002) terms as the natural supporters and healers such as the family, friends and community.

\section{CONCLUSION REMARKS}

It is clear that child sacrifice poses a significant challenge to the survivors and their families. The unique circumstances that surround the kidnapping of the child, the actual mutilation as well and injuries or beheading involved in the individual cases imply different experiences and thus challenges experienced by the respective survivors and their families. The unique circumstances are also associated with differing experiences of trauma, coping and recovery prospects. Cases that involve loss of the children's lives may also be experienced differently. Trauma is exacerbated in instances when the accomplice and perpetrator may be a well-known is a neighbor of family member. This may cultivate undesirable competing reaction among the aggrieved - "fight or flight" where some contemplate revenge on the one hand and others feel insecure anymore in their incumbent residences one the other hand.

The availability, accessibility and affordability of treatments for trauma are essential for the survivors and their families to cope with child sacrifice. In the Ugandan context, however, structural barriers such as the limited number of specialist mental health professionals, stigma associated with mental health services and lack of awareness regarding the available mental health services often hinder the seeking and utilization of relevant interventions. The growing 
individualistic tendencies associated with urbanization, poverty and modernizations also imply that the extended family may not be able to provide social support to many individuals and families affected by child sacrifice. We therefore recommend that addressing psychosocial problems associated with child sacrifice requires dedicated investment in psychosocial support and related services to help enhance the coping capacities of the survivors and their families.

\section{References}

[1] Adshead Gwen, Many major personal disasters are never reported in the press at all: (Treatment of Victims of Trauma, Journal of continuing Professional Development Advances in Psychiatric Treatment 1 (1995) 161-169.

[2] Allen G. Jon, Coping with Trauma: The Menninger Clinic, 2010. Available at http://www.menningerclinic.com/printablebro/coping_trauma05.htm

[3] ANPPCAN Uganda (n.d.), Case Story of John (not real names): a survivor of child sacrifice.

[4] Binoga Moses, The State of Child Sacrifice in the Country: A Paper Presented during the National Workshop on Child Sacrifice at Hotel Royale, Kampala, $5^{\text {th }}$ Nov 2009.

[5] Dass-Brailsford Priscilla, A Practical Approach to Trauma: Empowering Interventions; Sage Publications, 2007.

[6] Herman L. Judith, Trauma and Recovery: Basic Books, 1992. Available at http://www.uic.edu/classes/psych/psych270/PTSD.htm

[7] Levin Patti, Common Responses to Trauma \& Coping Strategies, 2004.

[8] Ljubica Vujadinovic, Child Sacrifice Becomes Booming Business: Uganda: Rare Survivors Suffer Lifetime Consequences, 2011.

[9] Play therapy for children website available at http://www.playtherapyforchildren.com/ Accessed 05.03.2012.

[10] Play therapy for children website available at: http://www.playtherapyforchildren.com/play.html Accessed 05.03.2012.

[11] Shalev A.Y., Treating Survivors in the Immediate Aftermath of Traumatic Events: In Rachel Yehuda (Ed.), Treating Trauma Survivors with PTSD; Washington DC: American Psychiatric Publishing, Inc. (2002) 157-188.

[12] The Advocacy Project Website, Lack of Evidence?": Interview 2 with Family Affected by Child Sacrifice Speaking on the Radio, Part II. Available at: http://advocacynet.org/wordpress-mu/jjenifer/2011/07/31/meet-the-volunteers-of-thegideon-foundation-against-child-sacrifice/ Accessed 28.02.2012.

[13] The Gale Encyclopedia of Mental Disorders, Ellent Hackery and Madeline Harris; (Eds.), 2003.

[14] Tucker-Ladd Clayton, Psychological Self-Help, 1996.

[15] Tuval-Mashiach Rivka; Freedman Sara; Bargai Neta; Boker Rut; Hadar, Hilit; and Shalev Y. Arieh, Coping with Trauma, Narrative and Cognitive Perspectives, Psychiatry 67(3) 2004. 
[16] Uganda Police, Status of the Child Sacrifice Situation in the Country, $2^{\text {nd }}$ December 2011.

[17] Uganda Police, Human Sacrifice Cases with Traditional Healers as Major Suspects, (2008 - $5^{\text {th }}$ July 2010).

[18] Uganda Radio Network website, Parents of Child Sacrifice Survivor Ask Police: To Protect Him, 2009.

[19] Webber J. M., Mascari J. B., Dubi M., \& Gentry, J. E., Moving forward, Issues in trauma response and treatment: In G. R. Walz, J. Bleuer, and R. K. Yep (Eds.), VISTAS; Compelling perspectives on counseling, Alexandria, VA: American Counseling Association (2006) 17-21. 